\title{
The chemistry and pharmacology of prostaglandins, with reference to human reproduction
}

\author{
Krister Gréen, Niels Christensen and Marc Bygdeman \\ Department of Clinical Chemistry and Department of Obstetrics and Gynecology, \\ Karolinska Hospital, S-104 01 Stockholm, Sweden
}

\section{Introduction}

The objective of this article is to give a brief summary of the biosynthesis, metabolism, physiology, and pharmacology of prostaglandins (PGs) in relation to human reproduction. These compounds are also of considerable interest in animal reproduction but those aspects will not be discussed.

A summary of the known routes of bioconversions of arachidonic acid is shown in Text-fig. 1. The oxidation of arachidonic acid through the action of lipoxygenases leads to formation of hydroperoxy acids which are reduced to hydroxy-eicosatetraenoic acids. Such conversions have been shown to occur in several tissues but the physiological significance of these hydroperoxy or hydroxy acids is unknown (Samuelsson, Granström, Gréen, Hamberg \& Hammarström, 1975).

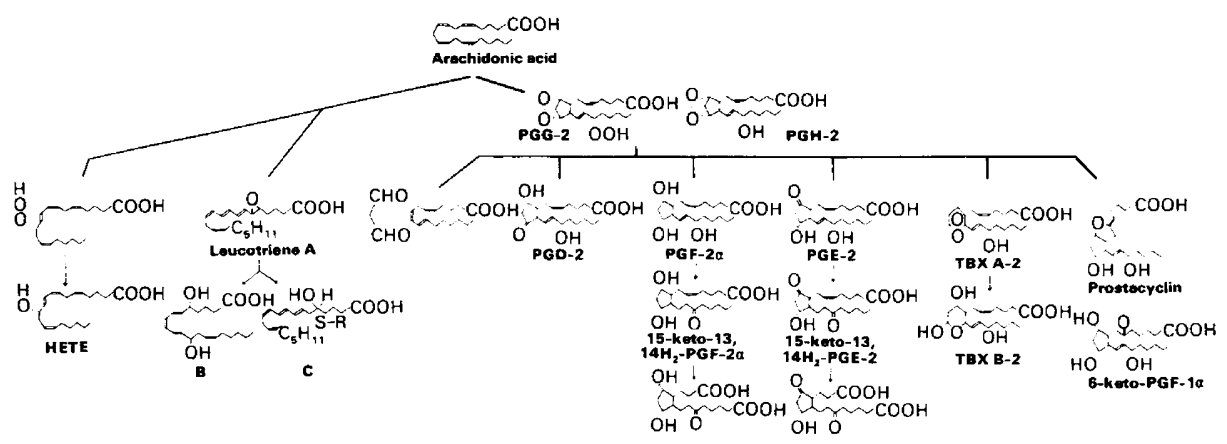

Text-fig. 1. Summary of some of the presently known bioconversions of arachidonic acid.

The routes leading to formation of leucotrienes have been demonstrated in normal and pathological leucocytes (Murphy, Hammarström \& Samuelsson, 1979; Parker, Huber, Koffman \& Falkenheim, 1979). The leucotrienes so far identified seem to be constituents of 'slow-reacting substance' preparations. The elucidation of the structures of some constituents of these substances now makes it possible to study biological effects of defined compounds. It is likely that leucotrienes play a role in conditions such as allergen-provoked asthma but nothing is known about their possible role in human reproduction.

The transformation of arachidonic acid into the cyclic endoperoxides PGG-2 and PGH-2 is catalysed by an enzyme, prostaglandin endoperoxide synthase, which has been purified from the seminal vesicles of bulls and rams (Miyamoto, Ogino, Yamamoto \& Hayaishi, 1976; Hemler, Lands \& Smith, 1976). These endoperoxides are key intermediates in the biosynthesis of PGE-2, PGF-2 $\alpha$, thromboxane (TBX) A-2 and PGI-2 (prostacyclin). 
The biosynthesis of TBX A-2 and TBX B-2 from arachidonic acid has been studied intensely in platelet suspensions (see Hamberg \& Samuelsson, 1974; Samuelsson et al., 1978). There is no doubt that the biologically active PGG-2, PGH-2 and TBX A-2 are important in regulating haemostasis in that they induce platelet aggregation and vasoconstriction. However, it has not yet been demonstrated that TBX A-2 has a physiological role outside the vascular system.

Prostacyclin formation occurs in vessel walls and some cell cultures (for a recent summary, see Moncada \& Vane, 1980). This compound has vasodilatory effects, it inhibits platelet aggregation and can also cause deaggregation of freshly aggregated platelets. Prostacyclin is clearly of importance in regulating haemostasis but it is uncertain whether it has a physiological role outside the vascular system.

The primary prostaglandins, PGE-2 and PGF-2 $\alpha$, and probably also the endoperoxides, have been shown to have physiological roles in human reproduction and this article will mainly be focussed on those aspects, to provide a biochemical and pharmacological background.

\section{Biosynthesis}

It is well known that prostaglandins are synthesized from three essential unsaturated fatty acids, 8,11,14-eicosatrienoic acid (dihomo- $\gamma$-linolenic acid), 5,8,11,14-eicosatetraenoic acid (arachidonic acid) and 5,8,11,14,17-eicosapentaenoic acid, which lead to the 1, 2 and 3 series respectively, e.g. PGE-1, PGE-2 and PGE-3 (for review, see Bygdeman \& Gréen, 1980). The quantitatively most important precursor acid is arachidonic acid and therefore most research efforts have been focussed on compounds of the 2 series.

The initial reaction in the series of events leading to prostaglandins is catalysed by prostaglandin endoperoxide synthase, yielding the endoperoxides PGG-2 and PGH-2. This enzyme has been purified and some of its properties have been characterized (Miyamoto et al., 1976; Hemler et al., 1976; van der Ouderaa, Buytenhek, Nugteren \& van Dorp, 1977). The reactions leading to the endoperoxides are inhibited by non-steroidal anti-inflammatory drugs. The endoperoxides can be further transformed into the compounds indicated in Text-fig. 1. Some of the enzymes involved have been partly purified and studied. Thus prostaglandin endoperoxide $\mathrm{E}$ isomerase catalyses formation of $\mathrm{PGE}-2$, a thromboxane $\mathrm{A}$ isomerase catalyzes formation of TBX A-2, several proteins catalyse formation of PGD-2 and prostaglandin endoperoxide F- $\alpha$ isomerase activity has been found in guinea pig uterus (see Samuelsson et al., 1978, for references). Several co-factors affect the reactions involved. The endoperoxides are unstable and degrade spontaneously in buffer to PGE-2 and PGD-2. Several compounds, e.g. glutathione and albumin, are known to affect the spectrum of products formed, enzymically or non-enzymically, from the endoperoxides.

It is clear that studies on the formation of PGs in various tissues might be very difficult to interpret. Artefactual formation of products might occur upon addition of cofactors and the spectrum of products found might not reflect the capacity of the tissue to synthesize those products but the capacity to synthesize endoperoxides. It is also necessary to keep in mind that the endoperoxides might be the most important products formed since they are biologically very active. Thus formation of PGE-2, in itself biologically active, in a tissue homogenate might not necessarily mean that it is the major compound of physiological importance.

Characteristic for the reactions leading to formation of PGs and related compounds is their rapidity. For example, in studies on the release of endoperoxide metabolites from aggregating platelets, the formation of TBX A-2 $(\mu \mathrm{g} / \mathrm{ml})$ and PGE-2 (several $\mathrm{ng} / \mathrm{ml}$ ), was maximal in $<5 \mathrm{~min}$ (Hamberg, Svensson \& Samuelsson, 1974). These findings are of considerable practical importance since they mean that analyses of thromboxanes, PGE-2 and PGF- $2 \alpha$ in peripheral plasma are not meaningful. For several years this was done but nowadays it is generally agreed that, whatever is found, some hundred $\mathrm{pg} / \mathrm{ml}$ of, for example, PGE-2 and PGF-2 $\alpha$, are formed 
during collection and isolation of the plasma. It is, however, probably meaningful to analyse PGs in the venous drainage from an organ releasing those compounds in high amounts (see McCracken, Barcikowski, Carlson, Gréen \& Samuelsson, 1973).

\section{Metabolism and assays}

The metabolism of PGs and related compounds has been studied in several species (for review see Samuelsson et al., 1975) and the structures of a great number of metabolites have been determined.

PGF- $2 \alpha$, injected intravenously into humans, disappears very rapidly from the circulation (estimated half-life $15 \mathrm{sec}$ ). More than $40 \%$ of the radioactivity appeared in plasma, $1.5 \mathrm{~min}$ after injection, as the major metabolite (Text-fig. 2). The estimated half-life of this metabolite in the circulation is $8 \mathrm{~min}$. It is formed through oxidation at carbon 15 and reduction of the $\Delta^{13}$-double bond. The enzymes responsible for this rapid inactivation of PGF are especially abundant in lung, liver and kidney. Further metabolic degradation occurs through $\beta$ - and $\Omega$-oxidations. The major urinary metabolite is formed through two steps of $\beta$-oxidation and $\Omega$-oxidation to a dicarboxylic acid (Text-fig. 2). PGE-2 is metabolized via the same reactions with similar kinetics.

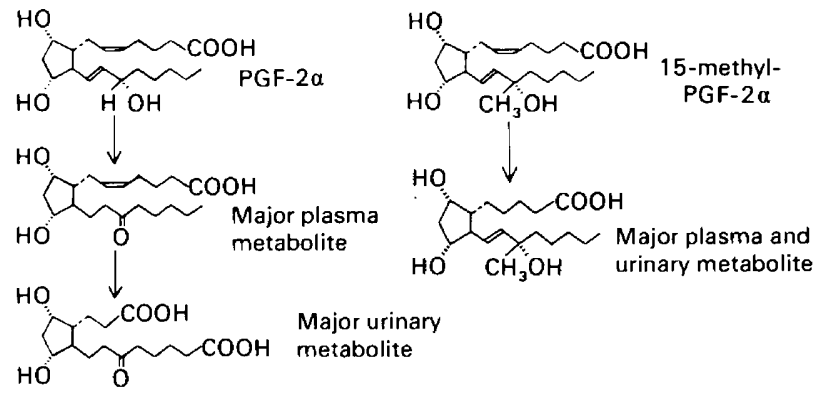

Text-fig. 2. Initial metabolic inactivation of PGF-2 $\alpha$ and 15(S)-15-methyl-PGF-2 $\alpha$.

The major plasma metabolite is neither formed nor further metabolized during collection of plasma and is therefore ideal for monitoring rather rapid (minutes, hours) changes in PG production in man. For changes of longer duration (hours, days) it seems desirable to measure the major urinary metabolite. Several radioimmunological assays and methods based on quantitative gas chromatography-mass spectrometry for measurements of those compounds have been developed (for recent reviews, see Samuelsson et al., 1975, 1978; Frölich, 1978). The reliability of different methods has been under debate for some years. We feel that it is fair to say that the radioimmunoassays are rapid and have a high capacity but are not as reliable as the physical assays.

In the following sections some data on the physiological and pharmacological roles of PGs and analogues, as evaluated with gas chromatography-mass spectrometric methods in our laboratory, will be described.

\section{Prostaglandins and the non-pregnant uterus}

Early in the studies of the effect of PGs on smooth muscle it was shown that PGs were very efficient in causing contraction of myometrial strips. In 1965 Pickles, Hall, Best \& Smith suggested that PGs might play a role in the etiology of dysmenorrhoea. Several reports on the 
beneficial effects of PG endoperoxide synthase inhibitors on symptoms of dysmenorrhoea have appeared. To find proof for an increased biosynthesis of PGs in patients with dysmenorrhoea we compared plasma levels of 15-keto-13,14-dihydro-PGF-2 $\alpha$ with those of eumenorrhoeic women. Dysmenorrhoeic women, that later responded well on PG synthetase inhibitors (PGSI), showed considerably higher levels than did non-dysmenorrhoeic women on the first day of menstruation (Text-fig. 3). The ranges were $53-105$ and $20-33 \mathrm{pg} / \mathrm{ml}$ respectively (Lundström \& Green, 1978). One dysmenorrhoeic patient did not respond to treatment with PGSI and before treatment she had a normal plasma level of the PGF-2 $\alpha$ metabolite, indicating that the reason for her symptoms was not an increased synthesis of PGs. Concentrations of the PGF-2 $\alpha$ in endometrial biopsies, taken under standardized conditions, showed a similar pattern. However, the data on tissue PG content are much less reliable than those for plasma levels, in view of what has been discussed above on biosynthesis, since artificial formation of PGs occurs quickly.

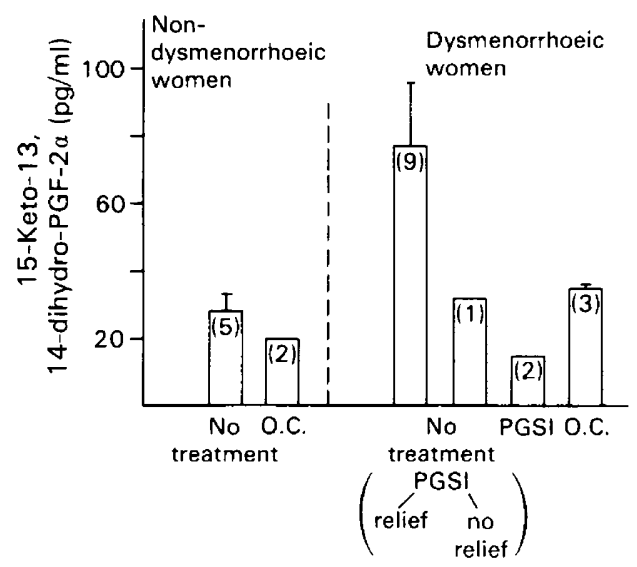

Text-fig. 3. Concentration of 15-keto-13,14-dihydro-PGF-2 $\alpha$ in plasma of women (no. in parentheses) on the first day of menstruation. O.C. $=$ oral contraceptives; PGSI $=$ prostaglandin synthetase inhibitors.

An increase of the major plasma metabolite of PGF-2 $\alpha$ means that an increase of PGF-2 $\alpha$ synthesis, and/or release into plasma, has occurred. This could mean that, on the one hand, more of the endoperoxides formed is converted to PGF- $2 \alpha$ with a reduction of formation of other endoperoxide products, or, on the other hand, that there was a considerable increase in formation of endoperoxides and all possible products (see Text-fig. 1) therefrom, but that the increase in PGF-2 $\alpha$ synthesis might be a minor pathway. In order to obtain a complete picture of the changes in production rates one would have to quantitate all possible products, or relevant metabolites, and this is at present not possible.

\section{Prostaglandins and the pregnant uterus}

The possible roles of PGs in human parturition have been reviewed repeatedly (Karim \& Rao, 1976; Wiqvist, 1975). It seems well established that at least PGF-2 $\alpha$ and PGE-2 are involved in inducing and maintaining uterine activity during human labour, because there are increases in the levels of PGF-2 $\alpha$ and PGE-2 within the amniotic cavity, the precursor fatty acid, arachidonic acid, in amniotic fluid (Keirse, Hicks, Mitchell \& Turnbull, 1977) and the plasma levels of the major metabolite of PGF-2 $\alpha$ (Gréen, Bygdeman, Toppozada \& Wiqvist, 1974a). Using specific physical assays it is not possible to demonstrate any systematic changes of the plasma levels of PGF- $2 \alpha$ during parturition, which is not unexpected in view of the artificial synthesis of prostaglandins that occurs during isolation of plasma (Green, Bygdeman \& 
Wiqvist, 1974b). This increase of PGF-2 $\alpha$ production has also been demonstrated by analysis of the major urinary metabolite of PGF-2 $\alpha$. A small gradual increase in the excretion of this metabolite was seen during pregnancy, with an abrupt rise during the day of parturition (Hamberg, 1974). It therefore seems well established that the synthesis of PGE-2 and PGF-2 $\alpha$ increases during labour. It is also possible that the PG endoperoxides exert a physiological effect. Several reports have indicated that PGI-2 can be formed, at least in the myometrium, but it is not known whether this compound has any role in regulating uterine contractility.

An increase of the plasma levels of 15-keto-13,14-dihydro-PGF-2 $\alpha$ has been shown during premature labour (Wiqvist, Lundström \& Green, 1975). This has led to treatment of this condition with PG synthetase inhibitors. However, it seems that PG synthesis is necessary to keep the ductus arteriosus open and this makes such treatment of doubtful value.

\section{Prostaglandins and abortion}

Studies on the smooth-muscle stimulating activity of PGs on the pregnant human uterus in vivo were first reported by Bygdeman, Kwon \& Wiqvist (1967). These studies initiated the development of PGs and PG analogues as abortifacients, a development which has led to methods for induction of second-trimester abortions which are non-invasive, quicker and safer than the traditional intra-amniotic injections of hypertonic or cell destroying solutions. Probably this development will also lead to non-surgical methods for self-administration up to 49 days of amenorrhoea.

During this development the pharmacology of PGs and PG analogues in the human being has been studied extensively at the Karolinska Institute and Hospital. Some of these investigations will be briefly described below. Gas chromatography-mass spectrometry were used for all quantitations described.

\section{Prostaglandin $F-2 \alpha$}

This PG was the first to be used for the induction of second-trimester abortions. Because of the very short half-life time in the circulation it was given as intravenous infusion. During infusion of PGF- $2 \alpha$ at a rate of $75 \mu \mathrm{g} / \mathrm{min}$ the plasma levels of PGF- $2 \alpha$ rose quickly to about 1 $\mathrm{ng} / \mathrm{ml}$ (including what was released from platelets during collection of plasma) and then quickly dropped when the infusion was interrupted (Text-fig. 4). The level of the major metabolite was about $33 \mathrm{ng} / \mathrm{ml}$ and no accumulation of PGF- $2 \alpha$ or the metabolite in the circulation occurred during infusion (Beguin et al., 1972). Since the amount of PGF-2 $\alpha$ given per minute is about twice the calculated total endogenous body production of this compound in females over $24 \mathrm{~h}$,

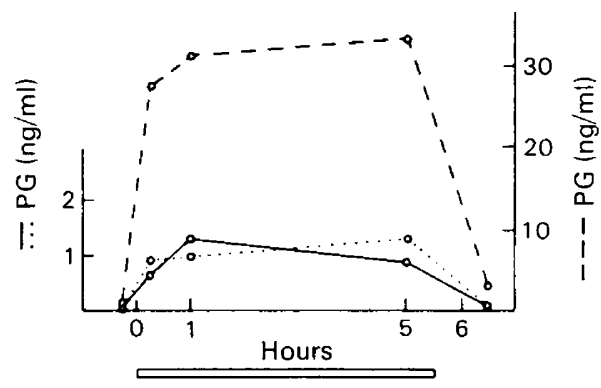

Text-fig. 4. Plasma levels of PGF-2 $\alpha$ (-), 15-keto-13,14-dihydro-PGF-2 $\alpha$ (---) and 13,14-dihydro-PGF- $2 \alpha(\cdots)$ during intravenous infusion of PGF- $2 \alpha(75 \mu \mathrm{g} / \mathrm{min})$ to man for $5 \cdot 5 \mathrm{~h}$ (horizontal bar). 
these data illustrate the enormous capacity in human beings to remove PGF-2 $\alpha$ from the circulation (Samuelsson, 1973). Data from 10 women, treated with PGF-2 $\alpha$ at a rate of 75 $\mu \mathrm{g} / \mathrm{min}$ to induce abortion, show a mean plasma concentration of $4.45 \mathrm{ng}$ PGF- $2 \alpha / \mathrm{ml}$ and 105 ng 15-keto-13,14-dihydro-PGF-2 $\alpha / \mathrm{ml}$, i.e. 10-70-fold higher than PGF-2 $\alpha$ (Beguin et al., 1972).

The disadvantages of giving an i.v. infusion for induction of abortion (impractical, rather high frequencies of gastrointestinal side effects) soon led to investigations of the extra- and intra-amniotic route for administration. This route is now a routine procedure in many countries.

The metabolic events were studied by intra-amniotic administration of tritium-labelled PGF-2 $\alpha$ (Granström, Gréen, Bygdeman, Toppozade \& Wiqvist, 1973; Gréen et al., 1974b). It was demonstrated that the drug was slowly metabolized and increasing amounts of 15 keto-13,14-dihydro-PGF-2 $\alpha$, 15-keto-PGF-2 $\alpha$ and 13,14-dihydro-PGF-2 $\alpha$ appeared in the amniotic cavity (Text-fig. 5). The half-life time of PGF-2 $\alpha$ was $13.5-20 \mathrm{~h}$. Analyses of metabolite profiles from fetal tissues and placenta indicated that those tissues were active in metabolizing PGF-2 $\alpha$. Quantitation in plasma of the major metabolite of PGF-2 $\alpha$ (15keto-13,14-dihydro-PGF-2 $\alpha$ ) demonstrated levels $\leqslant 5 \mathrm{ng} / \mathrm{ml}$. These concentrations of the metabolite (see Text-fig. 4) indicate that at most about $100 \mathrm{pg}$ PGF- $2 \alpha / \mathrm{ml}$ could be circulating. This is a concentration that per se cannot give rise to the gastrointestinal side effects seen following intra-amniotic administration of PGF-2 $\alpha$. The occurrence of side effects does not, therefore, depend on resorption of intact PGF-2 $\alpha$ into the circulation.

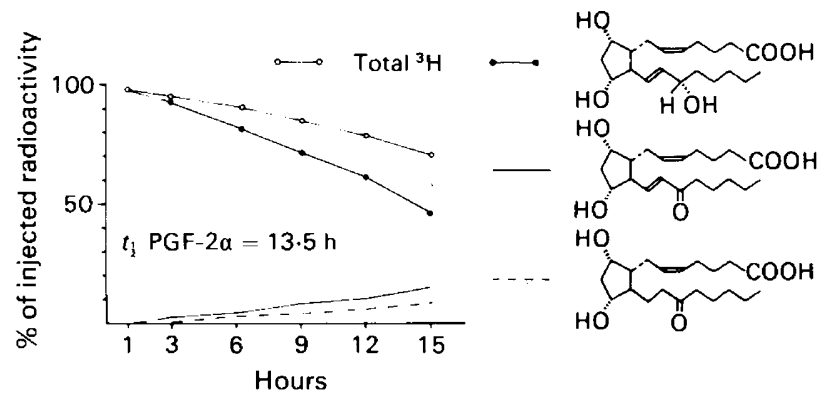

Text-fig. 5. Disappearance of PGF-2 $\alpha$ and appearance of metabolites in amniotic fluid following intra-amniotic administration of $40 \mathrm{mg}$ tritium-labelled PGF-2 $\alpha$ for interruption of a second-trimester pregnancy.

\section{5(S)-15-methyl-PGF-2a}

The short half-life of PGF- $2 \alpha$ makes it less suitable for systemic administration other than by i.v. infusion. Metabolic studies demonstrated that the rapid inactivation was due to oxidation at carbon 15. Blockade of this reaction was achieved by introduction of a methyl group at this carbon, 15 (S)-15-methyl-PGF-2 $\alpha$. This analogue has a considerably longer half-life time, $8 \mathrm{~min}$, in the circulation than PGF-2 $\alpha$ and was therefore more suitable for other routes of delivery (Text-fig. 2).

Intravenous infusion of 15 -methyl-PGF-2 $\alpha$ at rates of 2.5 and $5 \mu \mathrm{g} / \mathrm{min}$ gave the plasma levels shown in Text-fig. 6 . The rate $2.5 \mu \mathrm{g} / \mathrm{min}$ gives rise to efficient contractions leading to abortion. Thus the 'therapeutic plasma level' of 15 -methyl-PGF-2 $\alpha$ for induction of abortion is about $1-1.2 \mathrm{ng} / \mathrm{ml}$. A doubling of the infusion rate resulted in a continuous increase in plasma level (Text-fig. 6). This demonstrates that the enzyme systems inactivating and eliminating 15-methyl-PGF- $2 \alpha$ from the circulation are overloaded if $5 \mu \mathrm{g} 15$-methyl-PGF- $2 \alpha / \mathrm{min}$ are introduced into the circulation (Green \& Bygdeman, 1977). Repeated intramuscular administration of 200-300 $\mathrm{\mu g}$ 15-methyl-PGF-2 $\alpha$ results in high levels in plasma 20-30 min after the 
injection which then slowly decline. Text-figure 7 shows plasma levels in 3 women given repeated intramuscular injections of 200 and $300 \mu \mathrm{g}$ every 3rd hour. At doses of $300-400 \mu \mathrm{g}$, therefore, a mean plasma level of about $1000 \mathrm{pg} / \mathrm{ml}$ should be achieved. This dose regimen has been successfully used for induction of abortion. However, the 'spikes' seen shortly after injection are probably the reason for the rather high frequency of side effects seen with intramuscular administration of this drug.

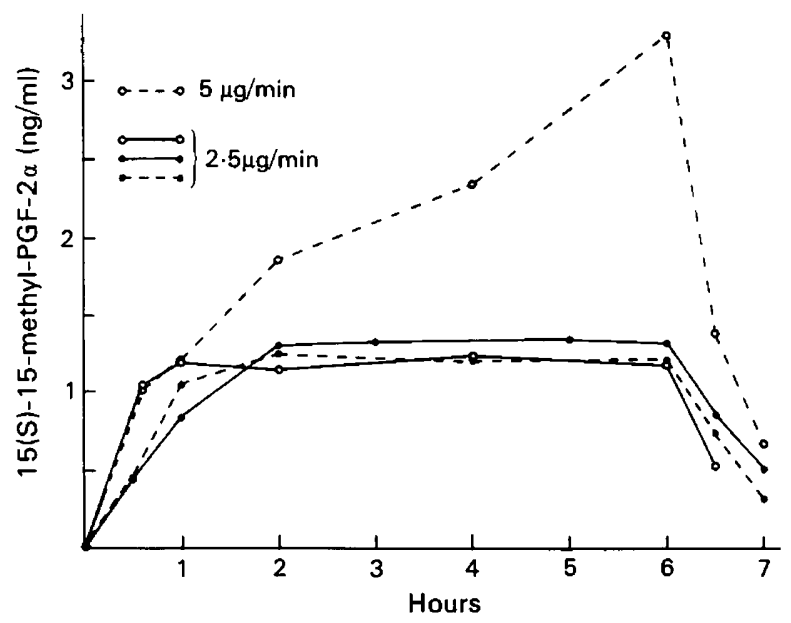

Text-fig. 6. Plasma levels of 15(S)-15-methyl-PGF-2 $\alpha$ during intravenous infusion for $6 \mathrm{~h}$ at rates of 2.5 and $5 \mu \mathrm{g} / \mathrm{min}$ to 4 women undergoing abortion.

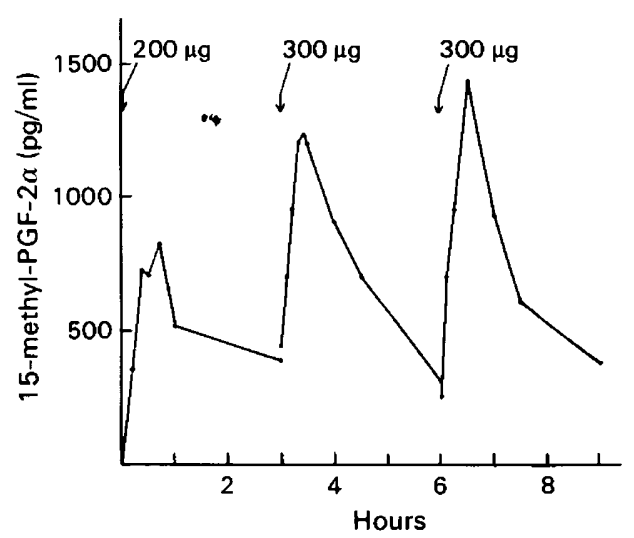

Text-fig. 7. Plasma levels of 15 -methyl-PGF- $2 \alpha$ in 3 patients receiving repeated intramuscular injections of the drug.

Intra-amniotic administration of 15 -methyl-PGF-2 $\alpha$ can also be used successfully for induction of second-trimester abortions. Studies with tritium-labelled drug have demonstrated that 15-methyl-PGF-2 $\alpha$ is slowly metabolized in the amniotic cavity to dinor-15-methyl-PGF-2 $\alpha$ (Green, Granström, Bygdeman \& Wiqvist, 1976). The half-life time of this drug is about twice that of PGF-2 $\alpha$. Since the two compounds are of the same polarity this probably also means that inside the uterine cavity the rapidity of metabolic inactivation is of importance for the duration of activity. This drug is also resorbed intact into the maternal circulation, giving plasma concentrations which contribute to the induced uterine contractility (Text-fig. 8). 


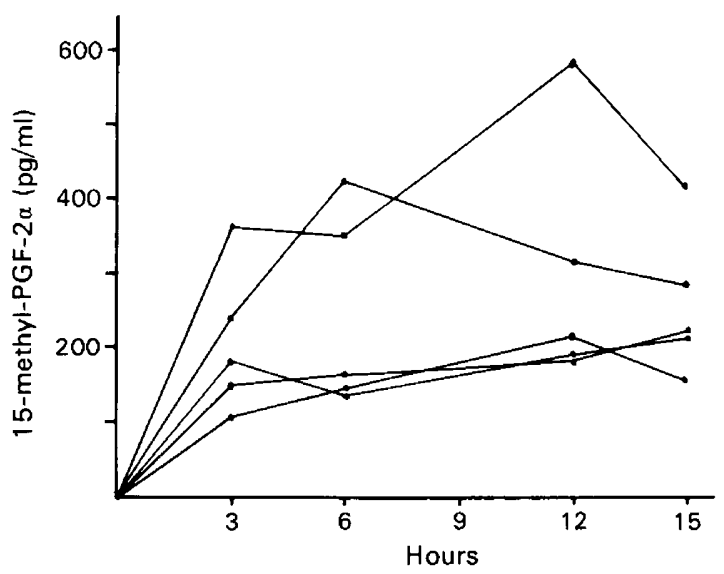

Text-fig. 8. Peripheral plasma levels of 15 -methyl-PGF-2 $\alpha$ following intra-amniotic administration of $2.5 \mathrm{mg}$ of this drug.

\section{5-Methyl-PGF-2a-methyl ester}

The relatively long half-life time of 15 -methyl-PGF-2 $\alpha$ made this analogue promising for the development of simpler routes of administration. The aim was to find formulations suitable for vaginal administration. To obtain a 'slow release device', mixtures of triglycerides were chosen as the delivery vehicle and the relatively lipid-soluble methyl ester was chosen since the free acid was released relatively quickly from the triglyceride mixture. Vaginal suppositories were first prepared using a fat with a melting point below body temperature. Such a vaginal suppository containing $1 \mathrm{mg} \mathrm{15-methyl-PGF-2} \alpha$-methyl ester gave plasma levels close to the desired 1000 $\mathrm{pg} / \mathrm{ml} 2-4 \mathrm{~h}$ after administration (Text-fig. 9). Since plasma contains esterases both the free acid and methyl ester form of the drug had to be analysed (Miller \& Magee, 1974). These plasma profiles and clinical data were the background for the dose regimen developed for interruption of second-trimester pregnancies (Bygdeman, Martin, Wiqvist, Gréen \& Bergström, 1974). Vaginal administration at 3-h intervals of such suppositories in the second trimester results in plasma levels around $1000 \mathrm{pg} / \mathrm{ml}$ and abortion in almost all women within $24 \mathrm{~h}$ (see Bygdeman et al., 1974).

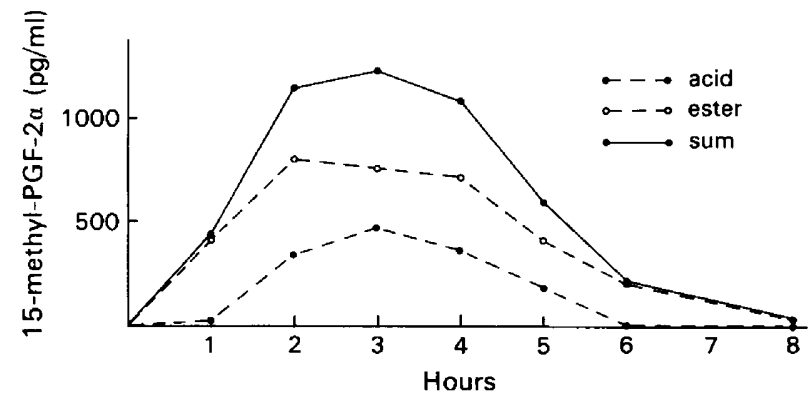

Text-fig. 9. Plasma levels of 15-methyl-PGF-2 $\alpha$ as free acid and methyl ester following vaginal administration of a suppository containing $1 \mathrm{mg}$ of the methyl ester of the drug in a triglyceride mixture with a melting point below body temperature.

Administration of vaginal suppositories at 3-h intervals is a drawback from a practical point of view, and therefore the development of a device capable of releasing the drug over a longer period of time was initiated. By testing different triglyceride bases and variation of the drug amounts a suitable formulation was identified. Vaginal administration of $3 \mathrm{mg} 15$-methyl- 
PGF-2 $\alpha$-methyl ester in a fat with a melting point around that of body temperature gave the desired plasma levels for 12-18 h (Text-fig. 10; Bygdeman et al., 1974). In clinical studies this suppository has been shown to be efficient in induction of abortion in the second trimester as well as the early first trimester, up to 49 days of amenorrhoea. The success rates were $92 \%$ within $24 \mathrm{~h}$ and 94.5\% respectively (Bygdeman et al., 1977; Gréen, Bygdeman \& Bremme, 1978).

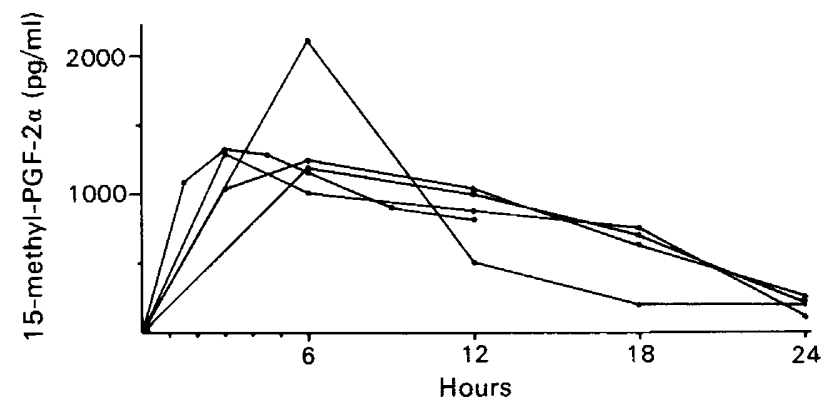

Text-fig. 10. Plasma levels of 15-methyl-PGF-2 $\alpha$ (sum of free acid and methyl ester) in patients given one vaginal suppository containing $3.0 \mathrm{mg}$ of the drug in a triglyceride mixture with a melting point around body temperature.

\section{Endogenous prostaglandins and induced abortion}

It has been demonstrated that extra-amniotic administration of hypertonic saline results in an increase of PGF-2 $\alpha$ in the amniotic fluid at the time when the uterus is contracting (Gustavii \& Green, 1972). This is probably due to osmotic damage of intrauterine tissues, e.g. decidua, which is known to cause formation of PGs. After administration of the long-acting vaginal suppository described above, the plasma levels of the drug decrease after about $12 \mathrm{~h}$ (Text-fig. $10)$. However, recordings of uterine activity demonstrated that the contractions were strong and often increasing after this time. Therefore the major plasma metabolites of PGE-2 and PGF-2 $\alpha$ were analysed in women undergoing second-trimester abortions with this treatment. The levels increased gradually during the induction and in most cases the highest levels were seen around the time of abortion (Text-fig. 11). The concentrations of the metabolites before administration were all in the range of those of normal healthy non-pregnant females, i.e. $15-40 \mathrm{pg} / \mathrm{ml}$. These data indicate that, following administration of long-acting vaginal suppositories containing 15-methyl-PGF-2 $\alpha$ for induction of abortion, the initially induced uterine contractility is due to the effect of the drug itself, but that after several hours there is an increasing, probably

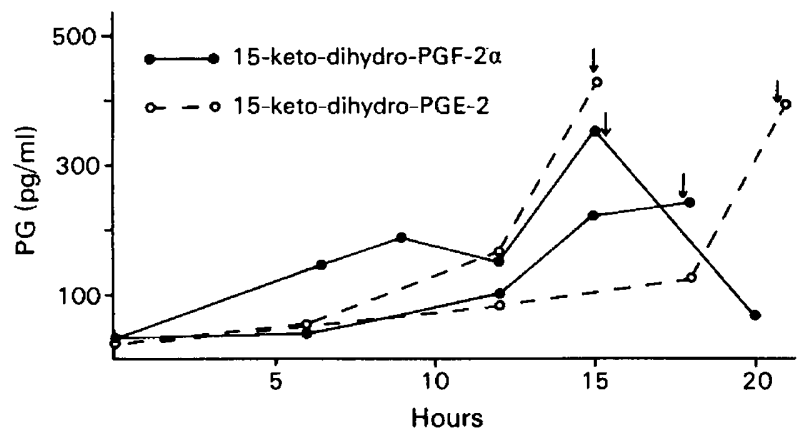

Text-fig. 11. Plasma levels of 15-keto-dihydro-PGF-2 $\alpha$ and 15-keto-dihydro-PGE-2 during induction of second-trimester abortions by vaginal administration of 15 -methyl-PGF- $2 \alpha$ methyl ester. Arrows indicate time of abortion. 
intrauterine, production of PGE-2 and PGF-2 $\alpha$. It is therefore likely that endogenous formation of these compounds will contribute to the stimulation of uterine contractility and thus to finalization of the abortion process.

Production of prostaglandins in reproductive tissues

All data indicating that PGs are involved in regulating uterine activity in parturition and other physiological or pathophysiological situations in which the uterus is contracting have
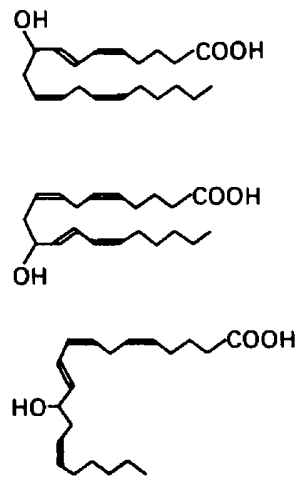
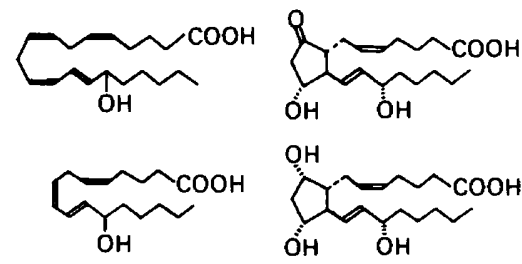

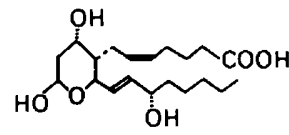

Text-fig. 12. Structures of compounds formed from $\left[{ }^{14} \mathrm{C}\right]$ arachidonic acid in whole homogenates of amniotic membrane obtained following vaginal delivery.
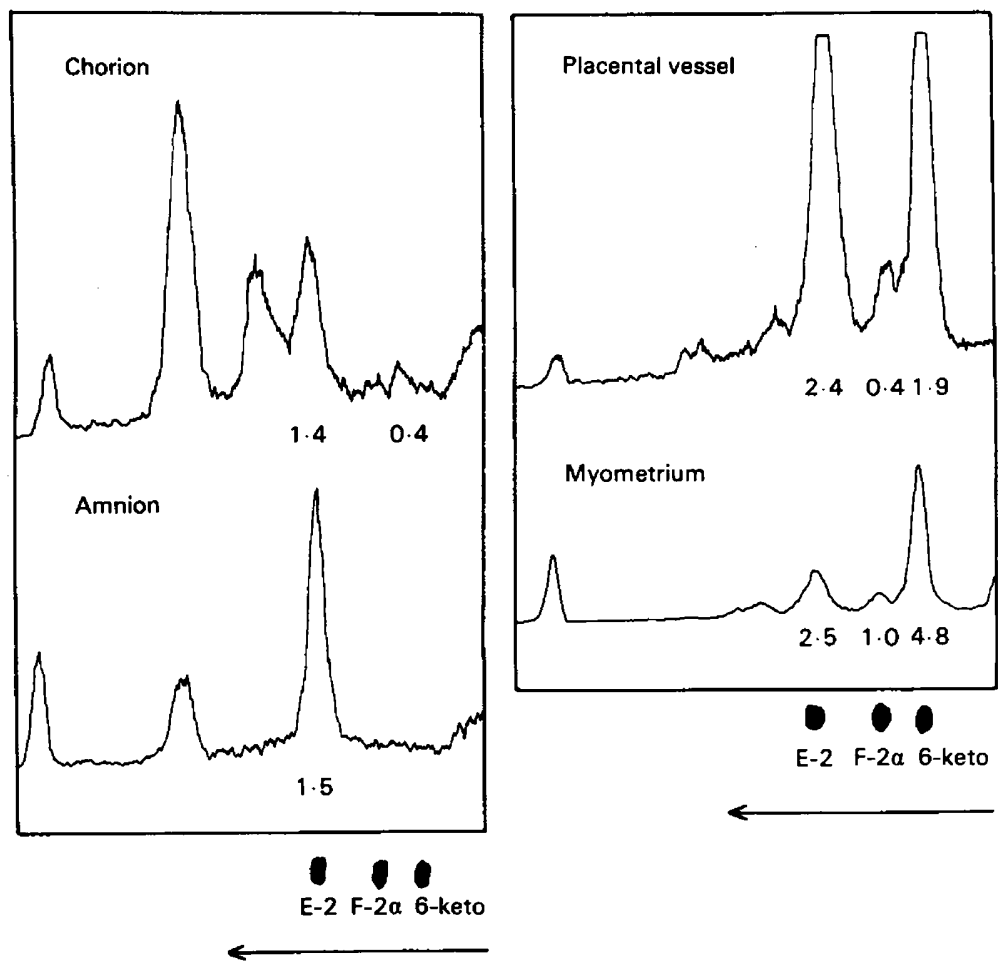

Text-fig. 13. Radio thin-layer chromatograms of the prostaglandins formed from $\left[{ }^{14} \mathrm{C}\right]-$ arachidonic acid in whole homogenates from tissues obtained at elective Caesarean section. The numerical values are $\%$. 
initiated in-vitro studies aiming at clarifying the mechanisms behind the changes in biosynthesis of these compounds. Arachidonic acid has been incubated under various conditions with homogenates of different tissues from the pregnant as well as non-pregnant human uterus (for a review, see Keirse, 1978).

We earlier investigated the conversion of $\left[{ }^{14} \mathrm{C}\right.$ larachidonic acid in whole homogenates of human amniotic membrane obtained after vaginal delivery. A summary of products identified with gas chromatography-mass spectrometry is shown in Text-fig. 12. The major products were PGE-2 (5\%) and 15-hydroxy-5,8,11,13-eicosatetraenoic acid (2-3\%), while very little PGF-2 $\alpha$ $(0.2 \%)$ and TBX B-2 $(0.3 \%)$ were found. No formation of PGI-2 could be demonstrated (Kinoshita \& Green, 1980). Part of the hydroxy acids, especially the 9-, 11- and 12-hydroxy eicosatetraenoic acids, might have been formed through auto-oxidation although heat-inactivated homogenates did not reveal such artefactual formation. These data demonstrate that about $5 \%$ of the arachidonate is oxidized to form endoperoxides (PGG and PGH) which are then converted (enzymically or non-enzymically) into mainly PGE-2 and 12-hydroxy-5,8,10-heptadecatrienoic acid (1-2\%). The relatively high conversion into 15-hydroxy-5,8,11,13-eicosatetraenoic acid could be of physiological interest since the unstable 15-hydroperoxy acid might be active in stimulating smooth muscle like other hydroperoxy acids.

We have initiated similar investigations with other tissues, i.e. whole homogenates of chorion, amnion, myometrium and placental arteries obtained at elective Caesarean section (Text-fig. 13). The most obvious, but not unexpected, findings are the rather high amounts of 6-keto-PGF-2a formed in the vessels and the myometrium.

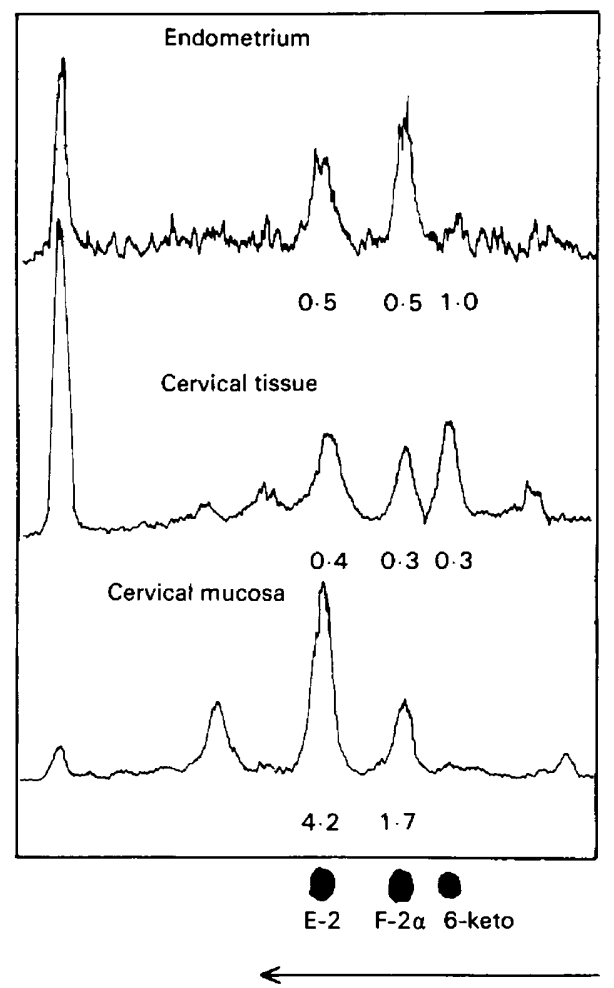

Text-fig. 14. Radio thin-layer chromatograms of prostaglandins formed from $\left[{ }^{14} \mathrm{C}\right]$ arachidonic acid in whole homogenates of endometrium, cervical tissue and cervical mucosa obtained from a patient in the secretory phase of the menstrual cycle. Numerical values are \%. 
Several clinical studies indicate that local or systemic administration of PGE compounds has a pronounced effect on the consistency of the cervix. A firm, rigid cervix turns into a soft, flexible cervix in 12-24 h. This suggests that PGs are involved in the ripening of the cervix in normal pregnancy. We have therefore studied the endogenous formation of prostaglandins in cervical tissue and mucosa. As can be seen in Text-fig. 14, the cervical mucosa is capable of converting arachidonic acid into PGs in vitro while the cervical tissue shows little activity.

Studies like these will probably result in a better understanding of the mechanisms involved in regulating uterine contractility during pregnancy and delivery. However, it is important to keep the special features of the enzymes, converting arachidonic acid into PGs and other products, in mind when interpreting the data obtained.

The studies described in this paper have mainly been supported by grants from the Swedish Medical Research Council to Professor Bengt Samuelsson, and the Expanded Programme of Research, Development and Research Training in Human Reproduction of the World Health Organization.

\section{References}

Beguin, F., Bygdeman, M., Gréen, K., Samuelsson, B., Toppozada, M. \& Wiquist, N. (1972) Analysis of prostaglandin $F_{2 a}$ and metabolites in blood during constant intravenous infusion of prostaglandin $F_{2 a}$ in the human female. Acta physiol. scand. 86, 430-432.

Bygdeman, M. \& Gréen, K. (1980) Prostaglandins and related compounds. In Gynecologic Endocrinology, 3rd edn, pp. 801-819. Eds J. J. Gold \& J. B. Josimovich. Harper \& Row, Hagerstown.

Bygdeman, M., Kwon, S. \& Wiqvist, N. (1967) The effect of prostaglandin $E$, on human pregnant myometrium in vivo. In Nobel Symposium 2, Prostaglandins, pp. 93-96. Eds S. Bergström \& B. Samuelsson. Almqvist and Wiksell, Stockholm.

Bygdeman, M., Martin, J.N., Wiqvist, N., Gréen, K. \& Bergström, S. (1974) Reassessment of systemic administration of prostaglandins for induction of midtrimester abortions. Prostaglandins 8, 157-169.

Bygdeman, M., Ganguli, A., Kinoshita, K., Lundström, V., Gréen, K. \& Bergström, S. (1977) Development of a vaginal suppository suitable for single administration for interruption of second trimester pregnancy. Contraception 15, 129-141.

Frölich, J.C. (Ed.) (1978) Methods in prostaglandin research. Advances in Prostaglandin and Thromboxane Research, Vol. 5. Raven Press, New York.

Granström, E., Gréen, K., Bygdeman, M., Toppozade, M. \& Wiqvist, N. (1973) Metabolic and quantitative studies in connection with intra-amniotic administration of prostaglandin $F_{2 u}$ for induction of therapeutic abortion. Life Sci. 12, 219-229.

Gréen, K. \& Bygdeman, M. (1977) Plasma levels of 15(S)-15-methyl-PGF $2 a$ following administration via various routes for induction of abortion. Prostaglandins 14, 1013-1023.

Gréen, K., Bygdeman, M., Toppozada, M. \& Wiqvist, N. (1974a) The role of prostaglandin $F_{2 a}$ in human parturition: endogenous levels of 15-keto-13,14dihydro-PGF ${ }_{2 \alpha}$ during labour. Am. J. Obstet. Gynec. 120, 25-31.
Gréen, K., Bygdeman, M. \& Wiqvist, N. (1974b) Kinetic and metabolic studies of prostaglandin $F_{2 \alpha}$ administered intra-amniotically for induction of abortion. Life Sci. 14, 2285-2297.

Gréen, K., Granström, E., Bygdeman, M. \& Wiqvist, N. (1976) Kinetic and metabolic studies on 15-methyl$\mathrm{PGF}_{2 \alpha}$ administered intra-amniotically for induction of abortion. Prostaglandins 11, 699-711.

Gréen, K., Bygdeman, M. \& Bremme, K. (1978) Interruption of early first trimester pregnancies by single vaginal administration of 15 -methyl-PGF $2 a$ methyl ester. Contraception 18, 551-560.

Gustavii, B. \& Gréen, K. (1972) Release of prostaglandin $F_{2 a}$ following injection of hypertonic saline therapeutic abortion. A preliminary study. Am. J. Obstet. Gynec. 114, 1099.

Hamberg, M. (1974) Quantitative studies of prostaglandin synthesis in man. Excretion of the major urinary metabolite of prostaglandins $F_{1 \alpha}$ and $F_{2 \alpha}$ during pregnancy. Life Sci. 14, 247-252.

Hamberg, M. \& Samuelsson, B. (1974) Prostaglandin endoperoxides. Novel transformations of arachidonic acid in human platelets. Proc. natn. Acad. Sci. U.S.A. 71, 3400-3404.

Hamberg, M., Svensson, J. \& Samuelsson, B. (1974) Prostaglandin endoperoxides. A new concept concerning the mode of action and release of prostaglandins. Proc. natn. Acad. Sci. U.S.A. 71, 38243828.

Hemler, M., Lands, W.E.M. \& Smith, W.L. (1976) Purification of the cyclooxygenase that forms prostaglandins. J. biol. Chem. 251, 5575-5579.

Karim, S.M.M. \& Rao, B. (1976) Prostaglandins in human reproduction. In Obstetric and Gynecological uses of Prostaglandins, pp. 1-21. Ed. S. M. M. Karim. MTP Press Ltd, Lancaster.

Keirse, M.J.N.C. (1978) Biosynthesis and metabolism of prostaglandins in the pregnant human uterus. $A d v$. Prostaglandin Thromboxane Res. 4, 87-102.

Keirse, M.J.N.C., Hicks, B.R., Mitchell, M.D. \& 
Turnbull, A.C. (1977) Increase of the prostaglandin precursor, arachidonic acid, in amniotic fluid during spontaneous labour. Br. J. Obstet. Gynaec. 84, 937-940.

Kinoshita, K. \& Gréen, K. (1980) Bioconversion of arachidonic acid to prostaglandins and related compounds in human amnion. Biochem. Med. 23, 185-197.

Lundström, V. \& Gréen, K. (1978) Endogenous levels of prostaglandin $F_{2 \alpha}$ and its main metabolites in plasma and endometrium in normal and dysmenorrheic women. Am. J. Obstet. Gynec. 130, 640-646.

McCracken, J.A., Barcikowski, B., Carlson, J.C., Gréen, K. \& Samuelsson, B. (1973) The physiological role of prostaglandin $F_{2 a}$ in corpus luteum regression. Adv. Biosci. 9, 599-624.

Miller, O.V. \& Magee, W.E. (1974) In vitro hydrolysis of prostaglandin $F_{2 a}$ esters by serum or plasma of different animal species. Prostaglandins 7, 29-38.

Miyamoto, T., Ogino, N., Yamamoto, S. \& Hayaishi, $\mathbf{O}$. (1976) Purification of Prostaglandin endoperoxide synthetase from bovine vesicular gland microsomes. J. biol. Chem. 251, 2629-2636.

Moncada, S. \& Vane, J.R. (1980) Prostacyclin in the cardiovascular system. Adv. Prostaglandin Thromboxane Res. 6, 43-60.

Murphy, R.C., Hammarström, S. \& Samuelsson, B. (1979) Leucotriene C: A slow-reacting substance from murine mastocytoma cells. Proc. natn. Acad. Sci. U.S.A. 76, 4275-4279.

Parker, C.W., Huber, M.M., Koffiman, M.K. \& Fal- kenheim, S.F. (1979) Characterization of the two major species of slow reacting substance from rat basophilic leukemia cells as glutathionyl thioethers of eicosatetraenoic acids oxygenated at the 5 position. Evidence that peroxy groups are present and important for spasmogenic activity. Prostaglandins 18, 673-686.

Pickles, V.R., Hall, W.J., Best, F.A. \& Smith, G.N. (1965) Prostaglandins in endometrium and menstrual fluid from normal and dysmenorrhoic subjects. J. Obstet. Gynaec. Br. Commonw. 72, 185-187.

Samuelsson, B. (1973) Quantitative aspects on prostaglandin synthesis in man. Adv. Biosci. 91, 7-14.

Samuelsson, B., Granström, E., Gréen, K., Hamberg, M. \& Hammarström, S. (1975) The biochemistry of prostaglandins. Ann. Rev. Biochem. 44, 669-695.

Samuelsson, B., Goldyne, M., Granström, E., Hamberg, M., Hammarström, S. \& Malmsten, C. (1978) Prostaglandins and Thromboxanes. Ann. Rev. Biochem. 47, 997-1029.

van der Ouderaa, F.J., Buytenhek, M., Nugteren, D.H. \& van Dorp, D.A. (1977) Purification and characterization of Prostaglandin Endoperoxide Synthetase from sheep vesicular glands. Biochim. Biophys. Acta 487, 315-331.

Wiqvist, N. (1975) Endogenous prostaglandins in normal pregnancy and labor. Int. Encyclopedia of Pharmacology and Therapeutics 1, 297-325.

Wiqvist, N., Lundström, V. \& Gréen, K. (1975) Premature labour and indomethacin. Prostaglandins 10, 515-526. 